\title{
Asymptomatic hyperglycaemia and major ischaemic heart disease events in Britain
}

\author{
Ivan J Perry, S Goya Wannamethee, Peter H Whincup, A Gerald Shaper
}

\begin{abstract}
Objective - To examine the association between non-fasting serum glucose concentrations and major ischaemic heart disease (IHD) events (fatal and non-fatal myocardial infarction).

Design - A prospective study.

Subjects - A population based sample of 7735 middle aged British men. Known diabetics, men with a glucose concentration $\geqslant 11 \cdot 1 \mathrm{mmol} / 1$ at screening, and hypertensive patients taking regular medication were excluded from the analysis. With exclusions $(n=509)$ and missing glucose values $(n=49)$, there were 7177 men available for analysis.
\end{abstract}

Main outcome measures - Major IHD events (fatal and non-fatal myocardial infarction) during $\mathbf{9 . 5}$ years follow up on all men.

Results - There were 505 major IHD events, 222 fatal and 283 non-fatal, in the 7177 men studied. There was a non-linear relation between the glucose concentration and the risk (per 1000 men per year) of all major IHD events and fatal IHD events, with the excess risk in the upper quintile of the glucose distribution ( $\geqslant 6.1 \mathrm{mmol} / \mathrm{l})$. The unadjusted relative risks (RR) in the upper glucose concentration quintile compared with the first to the fourth quintiles combined were $1.4(95 \% \mathrm{CI} 1 \cdot 1,1 \cdot 7)$ for all events and $1.3(95 \% \mathrm{CI} 1.0,1.7)$ for fatal events. Adjustment for age, smoking, occupational status, body mass index, physical activity, systolic blood pressure, total and high density lipoprotein cholesterol, and triglyceride concentrations had a minimal effect on these relative risk estimates. This non-linear relationship between the serum glucose concentration and the risk of a major IHD event was observed in men with no evidence of IHD at screening ( $n=$ $5518)$ but not in men with IHD $(n=1659)$. In the former group, the RR (adjusted for major coronary risk factors) for all major IHD events in the upper quintile relative to the lower quintiles combined was 1.5 $(95 \%$ CI $1 \cdot 2,2 \cdot 0)$ and for fatal IHD events was $1.8(95 \%$ CI $1 \cdot 1,2 \cdot 6)$.

Conclusion - These data suggest that asymptomatic hyperglycaemia is an independent risk factor for major IHD events.

\section{(f Epidemiol Community Health 1994;48:538-542)}

Non-insulin dependent diabetes mellitus is associated with an increased risk of ischaemic heart disease (IHD). ${ }^{1}$ The association with
IHD, as with other manifestations of diabetic large vessel disease, is only partly explained by the higher prevalence of vascular risk factors associated with diabetes, such as obesity, hypertension, and hyperlipidaemia. ${ }^{23}$ Diverse explanations have been proposed for the excess of IHD in non-insulin dependent diabetes mellitus. These include direct atherogenic effects of glucose, the role of insulin resistence and hyperinsulinaemia as a unifying link between non-insulin dependent diabetes mellitus and IHD, and the possibility that these conditions share common genetic or environmental antecedents, or both. ${ }^{45}$

By contrast, data on the nature and form of the association between asymptomatic hyperglycaemia and IHD are inconsistent, with negative findings, ${ }^{6}$ threshold effects, ${ }^{278}$ and positive linear associations ${ }^{910}$ reported. Many previous studies have lacked power to study the relationship between blood glucose and IHD. Most have documented fewer than 200 events, a relatively small number given the low reliability with which glucose is estimated. ${ }^{11} 12$ Relatively few studies have adequately adjusted for the range of possible confounding factors. In no previous study of this association, has it been possible to adjust simultaneously for the high density lipoprotein (HDL) cholesterol concentration, serum triglycerides, and for the level of physical activity ${ }^{13-14}$ - potential confounding factors that are of fundamental importance. In this study we examine the relation between asymptomatic hyperglycaemia and IHD in a population based sample of middle aged British men. There were over 500 major IHD events and we have adjusted for all major coronary risk factors including high density lipoprotein (HDL) cholesterol, triglycerides, and physical activity.

\section{Methods}

In the British Regional Heart Study, 7735 men aged 40 to 59 years were selected at random from the age-sex registers of one group general practice in each of 24 towns in England, Wales, and Scotland, and examined between 1978 and 1980 . The criteria for selecting the towns, general practices, and subjects and details of the respondents, data collection, and measurement of serum glucose and lipids have been described. ${ }^{15-18}$ The overall response rate was $78 \%$. There were 49 men with missing glucose data. Known diabetics at screening $(n=118)$ and hypertensives undergoing treatment $(n=362)$ were excluded from the analysis at the outset, the latter in view of the adverse effect of antihypertensive therapy, in particular thiazide di- 
uretics, on plasma glucose concentrations. ${ }^{19} \mathrm{~A}$ group of 29 men with a serum glucose concentration $\geqslant 11 \cdot 1 \mathrm{mmol} / \mathrm{l}$ at screening was also excluded, given the high probability of undiagnosed diabetes in this group. Hence, the data upon which the primary analyses were performed, refers to a total of 7177 men. In a subsidiary analysis (to minimise the possibility that men with undiagnosed diabetes were included in the study), we excluded an additional group of 100 men who developed non-insulin dependent diabetes over the subsequent 9.5 years of follow up. Cases of non-insulin dependent diabetes mellitus were ascertained by means of a questionnaire sent to the men at year 5 of follow up and by systematic periodic review of practice records. ${ }^{20}$

Non-fasting blood samples were obtained between 08.30 and 18.30. Serum glucose was analysed by commercially available automated analyser (Technicon SMA 12/60) and the time of sampling was noted. ${ }^{17}$ Less than $1 \%$ of the intersubject variance in the serum glucose concentration was attributable to the time of sampling. $^{21}$

\section{PHYSICAL ACTIVITY}

A physical activity index, which is predictive of major cardiovascular end points, ${ }^{13}$ was derived from an exercise questionnaire administered at the initial visit. Based on this index, the men were grouped into six broad physical activity categories: inactive $(n=602)$, occasional $(n=$ 2133), light $(n=1646)$, moderate $(n=1131)$, moderately vigorous $(n=1067)$, and vigorous $(n=503)$. Physical activity data were missing for 95 men. Men whose level of activity was moderate or higher were characterised as physically active.

\section{PREVALENT IHD}

The men were asked whether a doctor had ever told them that they had angina or myocardial infarction (heart attack, coronary thrombosis), stroke, and a number of other disorders. The (WHO) Rose questionnaire was administered to all men at the initial examination and a three-orthogonal lead ECG was recorded at rest. Prevalent IHD at screening was defined on the basis of any or all of the following criteria: recall of doctor diagnosis of angina or heart attack, a Rose questionnaire response indicating angina or possible myocardial infarction, and ECG evidence of definite or possible myocardial ischaemia or infarction. ${ }^{22} 23$

\section{FOLLOW UP}

Over $99 \%$ of study participants have been followed for morbidity and mortality for 9.5 years. Full details of follow up procedures have been published and the criteria for fatal and nonfatal major IHD events have been described. ${ }^{1520}$ Major IHD events refer to fatal and non-fatal myocardial infarction. Information on death was obtained through the established "tagging" procedures provided by the National Health Service registers in Southport (England and
Wales) and Edinburgh (Scotland). A non-fatal myocardial infarction was diagnosed according to WHO criteria - that is, an event which satisfied at least two of the following criteria: (a) preceded by severe prolonged chest pain, (b) ECG evidence of myocardial infarction, (c) cardiac enzyme changes associated with myocardial infarction. Fatal events were defined as deaths from IHD (International Classification of Disease 9 th revision: codes 410-414) as the underlying cause. After 9.5 years follow up on all study participants there had been 505 major IHD events, 222 fatal and 283 non-fatal. Individuals who had both a non-fatal and fatal myocardial infarction over the follow up period were classified as having had a fatal event.

\section{STATISTICAL ANALYSIS}

The risk of major IHD events was examined by quintile of serum glucose, with adjustment for confounding factors by fitting the Cox proportional hazards model. Age, body mass index, systolic blood pressure, total cholesterol, HDL cholesterol, and triglyceride concentration were fitted as continuous variables in the model. As data on triglyceride concentrations were not available for six towns, the analysis in which we adjusted for this factor was confined to a group of 5307 men. Social class was fitted as six dummy variables (seven social class groups), physical activity as five variables (six categories), alcohol as four variables (five categories, none, occasional, light, moderate, heavy), and smoking as four dummy variables (five groups, never, ex-smokers, light, moderate, and heavy).

We adjusted the IHD-glucose relation for confounding factors in three stages. Initially we adjusted for age, then body mass index, physical activity, smoking status, alcohol intake, and occupational status were added and in the third stage, systolic blood pressure, total cholesterol, HDL cholesterol, and triglycerides were added to the model. As there was an interaction with prevalent IHD at screening, men with IHD $(n=5518)$ and without IHD $(n=1659)$ at the baseline examination were considered separately in the principal analysis.

\section{Results}

A non-linear relation was observed between the glucose concentration and the risk (per 1000 men per year) of all major IHD events and fatal IHD events. There was a significant increase in risk at or above a serum glucose concentration of $6 \cdot 1 \mathrm{mmol} / 1$ (80th centile). The unadjusted relative risk (RR) in the upper glucose quintile compared with the first to the fourth quintiles combined was 1.4 (95\% CI $1 \cdot 1,1 \cdot 7)$ for all events and $1.3(95 \%$ CI 1.0 , 1.7) for fatal events (table 1).

The distribution of major coronary risk factors was examined in the upper quintile relative to the other four quintiles. Significantly more men whose serum glucose was in the upper quintile were engaged in manual occupations and a higher proportion were overweight or obese (body mass index $\geqslant 28 \mathrm{~kg} / \mathrm{m}^{2}$ ) (table 2 ). 
Table 1 Rate of ischaemic heart disease (IHD) events (all events and fatal events, unadjusted) per 1000 men per year by quintile of serum glucose concentration (nonfasting)

\begin{tabular}{|c|c|c|c|c|c|}
\hline \multirow[b]{2}{*}{$\begin{array}{l}\text { Glucose } \\
\text { (mmol/l) }\end{array}$} & \multirow[b]{2}{*}{ No of men } & \multicolumn{2}{|l|}{ All events } & \multicolumn{2}{|l|}{ IHD deaths } \\
\hline & & No of events & $\begin{array}{l}\text { Rate } \\
(\%)\end{array}$ & No of deaths & $\begin{array}{l}\text { Rate } \\
(\%)\end{array}$ \\
\hline $\begin{array}{l}<4 \cdot 8 \\
4 \cdot 9-5 \cdot 2 \\
5 \cdot 3-5 \cdot 5 \\
5 \cdot 6-6 \cdot 0 \\
\geqslant 6 \cdot 1\end{array}$ & $\begin{array}{l}1413 \\
1701 \\
1221 \\
1407 \\
1435\end{array}$ & $\begin{array}{r}96 \\
116 \\
80 \\
85 \\
128\end{array}$ & $\begin{array}{l}7 \cdot 2 \\
7 \cdot 2 \\
6 \cdot 9 \\
6 \cdot 4 \\
9 \cdot 4\end{array}$ & $\begin{array}{l}45 \\
56 \\
43 \\
24 \\
54\end{array}$ & $\begin{array}{l}3.4 \\
3.5 \\
3.7 \\
1.8 \\
4.0\end{array}$ \\
\hline
\end{tabular}

Table 2 Distribution of cardiovascular risk factors (mean (SD) or \%) in the first of the fourth glucose quintiles combined compared with the fifth glucose quintile

\begin{tabular}{|c|c|c|}
\hline & Glucose $<6.1 \mathrm{mmol} / \mathrm{l}$ & Glucose $\geqslant 6.1 \mathrm{mmol} / \mathrm{l}$ \\
\hline No of men & 5742 & 1464 \\
\hline Glucose* $(\mathrm{mmol} / \mathrm{l})$ & $5 \cdot 1$ & $7 \cdot 0$ \\
\hline Age $(y)$ & $49.9(5 \cdot 8)$ & $50.6(5 \cdot 8)$ \\
\hline Current smokerst (\%) & $42 \cdot 6$ & $37 \cdot 5$ \\
\hline Manual occupationt (\%) & $57 \cdot 6$ & $63 \cdot 8$ \\
\hline Obeset (\%) & 17.5 & $22 \cdot 7$ \\
\hline Active (\%) & $38 \cdot 0$ & $38 \cdot 3$ \\
\hline Moderate drinkers $\$(\%)$ & $26 \cdot 6$ & $28 \cdot 1$ \\
\hline Systolic BPf (mmHg) & $142.8(19.8)$ & $150.7(21.7)$ \\
\hline Diastolic BP (mmHg) & $81.6(12.8)$ & $82.6(13.7)$ \\
\hline Cholesterol $(\mathrm{mmol} / \mathrm{l})$ & $6 \cdot 29(1 \cdot 04)$ & $6 \cdot 28(1.04)$ \\
\hline HDL-cholest $\dagger(\mathrm{mmol} / \mathrm{l})$ & $1.16(0.26)$ & $1.13(0.27)$ \\
\hline Triglyceride*t $(\mathrm{mmol} / \mathrm{l})$ & 1.67 & 1.93 \\
\hline Evidence of IHD $\ddagger(\%)$ & $22 \cdot 3$ & $25 \cdot 3$ \\
\hline
\end{tabular}

* Geometric mean.

\$Daily 3-6 units of alcohol and weekend $>6$ units.

Table 3 Relative risk (RR) of major ischaemic heart disease events in the upper quintile of serum glucose $(n=1435)$ compared with the first to fourth quintiles combined

\begin{tabular}{|c|c|c|}
\hline $\begin{array}{l}\text { Adjusted } \\
\text { for }\end{array}$ & $\begin{array}{l}\text { All infarcts } \\
R R(95 \% C I)\end{array}$ & $\begin{array}{l}\text { Fatal infarcts } \\
R R(95 \% C I)\end{array}$ \\
\hline $\begin{array}{l}\text { Age (y) } \\
\text { Age, smoking, } \\
\text { alcohol intake, } \\
\text { occupational status, } \\
\text { physical activity, } \\
\text { and body mass index } \\
\text { Above + systolic blood pressure, } \\
\text { total cholesterol, } \\
\text { and HDL cholesterol }\end{array}$ & $\begin{array}{l}1.34(1 \cdot 1,1 \cdot 6) \\
1.29(1.06,1.6)\end{array}$ & $\begin{array}{l}1 \cdot 27(0 \cdot 9,1 \cdot 7) \\
1 \cdot 26(0 \cdot 9,1 \cdot 7)\end{array}$ \\
\hline
\end{tabular}

Table 4 Relative risk (RR) of major ischaemic heart disease events in the upper quintile of serum glucose ( $n=1074$ ) compared with the first to fourth quintiles combined, in men without evidence of ischaemic heart disease at the baseline examination

\begin{tabular}{lll}
\hline $\begin{array}{l}\text { Adjusted } \\
\text { for }\end{array}$ & $\begin{array}{l}\text { All infarts } \\
R R(95 \% \mathrm{CI})\end{array}$ & $\begin{array}{l}\text { Fatal infarts } \\
R R(95 \% \mathrm{CI})\end{array}$ \\
\hline $\begin{array}{l}\text { Age (y) } \\
\begin{array}{l}\text { Age, smoking, } \\
\text { alcohol intake, }\end{array}\end{array}$ & $1 \cdot 60(1 \cdot 3,2 \cdot 1)$ & $1 \cdot 68(1 \cdot 1,2 \cdot 5)$ \\
$\begin{array}{l}\text { occupational status, } \\
\text { physical activity, } \\
\text { and body mass index }\end{array}$ & & \\
$\begin{array}{l}\text { Above +systolic blood pressure, } \\
\text { total cholesterol, } \\
\text { and HDL cholesterol }\end{array}$ & $1.68(1 \cdot 3,2 \cdot 2)$ & $1.88(1 \cdot 3,2 \cdot 8)$ \\
\hline
\end{tabular}

There were significantly fewer smokers in the upper glucose quintile, the systolic blood pressure and triglyceride level were significantly higher and the HDL cholesterol concentration was significantly lower. The proportion of physically active men and the proportion of moderate drinkers were similar in the two groups. The prevalence of IHD at the initial examination was significantly higher in the upper glucose quintile. Differences in the distribution of blood pressure and serum lipids and in the prevalence of IHD between the upper and four lower serum glucose quintiles remained significant after adjustment for age, occupational status, and body mass index (BMI).

After adjustment for the major coronary risk factors, the increased risk for all myocardial infarction and for fatal infarction in the upper glocuse quintile was minimally attenuated and

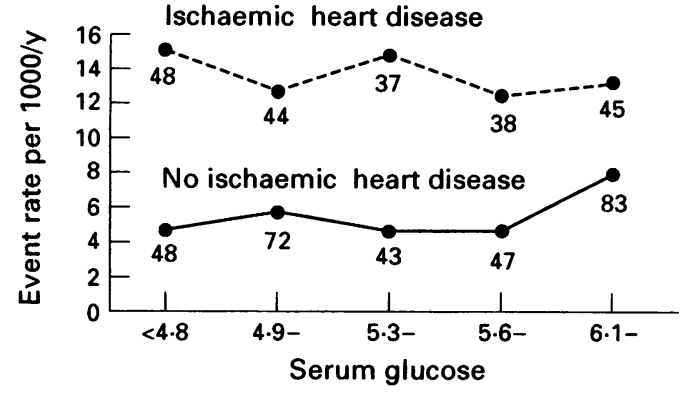

Major ischaemic heart disease event rate in relation to serum glucose concentration in men with and without ischaemic heart disease at screening.

remained significant for all events (table 3 ).

The non-linear relationship between the glucose concentration and the risk of IHD observed in the entire group, was clearly evident in men free of IHD $(n=5518)$, but not in those with evidence of IHD at screening (figure). In those without IHD at baseline, the age adjusted $R R$ in the upper glucose quintile relative to the rest were $1.6(95 \%$ CI $1.3,2 \cdot 1)$ for all major events and $1.7(95 \% \mathrm{CI} 1 \cdot 1,2 \cdot 5)$ for all fatal events (table 4). These effects were not attenuated by adjustment for smoking, social class, level of physical activity, and BMI. Further adjustment for systolic blood pressure and total and HDL cholesterol had a minimal effect on the association between glucose and IHD (table 4). No relationship between glucose and the risk of subsequent myocardial infarction was observed in men with pre-existing IHD at screening.

There was a significant positive correlation between serum glucose and triglyceride concentrations $(r=0.12, p<0.0001)$. The triglyceride concentration, however, is not an independent predictor of IHD events in this study once adjustment for blood cholesterol has been carried out. ${ }^{24}$ Hence, adjustment for the triglyceride concentration did not attenuate the increased IHD risk observed in the upper glucose quintile in the entire group or in men without evidence of IHD at screening.

We detected no evidence of a further increase in the risk of IHD at the 90 th or 95 th glucose centiles. The glucose-IHD association was unaltered when the 100 men known to have developed non-insulin-dependent diabetes during the 9.5 years of follow up were excluded. In this analysis, the age adjusted RRs for all events in the upper glucose quintile relative to the rest were $1.31,(95 \% \mathrm{CI}, 1.1,1.6)$ in the entire group and $1.60(95 \% \mathrm{CI}, 1 \cdot 2,2 \cdot 1)$ in men free of IHD at screening.

\section{Discussion}

We have observed a non-linear relationship between non-fasting glucose and the risk of major IHD events in a population based sample of middle aged British men. This association was observed only in men free of IHD at the screening examination. In the latter there was a substantially increased risk of major IHD events in the upper serum glucose quintile which was independent of major cardiovascular risk factors, including physical activity and lipid 
levels. In particular, the association was unaltered on adjustment for the HDL cholesterol concentration. HDL cholesterol concentrations are consistently low in subjects with abnormal glucose tolerance, both non-insulin dependent diabetes and impaired glucose tolerance, ${ }^{25}$ and it has been suggested that confounding due to this factor might explain the association between asymptomatic hyperglycaemia and IHD. ${ }^{7}$ Hence these findings provide further evidence of the fundamental role of abnormalities of glucose homeostasis in the development of atherosclerosis, and they highlight the need for an integrated approach to the prevention of IHD and glucose intolerance.

Non-fasting blood samples were obtained in this study to ensure a high response rate from this uniquely representative, population based sample. Though fasting samples or those taken after glucose load would have provided a more precise and reliable measure of glycaemic status, it may be argued that such imprecision will attenuate rather than exaggerate the association with IHD events which we have described.

We considered the possibility that the increased risk of IHD observed in the upper glucose quintile might have resulted from the inclusion of undiagnosed diabetics, in whom an increased risk of heart disease would be expected. This is unlikely, given that we excluded men with glucose $\geqslant 11.1 \mathrm{mmol} / 1$ at screening from the study and that the findings were unaltered in an analysis in which we also excluded men who developed non-insulindependent diabetes over the subsequent 9.5 years of follow up. No single measure of glycaemic status employed in an epidemiological study, whether casual, fasting, or after glucose load, is without error. Hence a degree of misclassification of diabetic status is inevitable. We would argue, however, that in a group of men with a casual glucose concentration $<11 \cdot 1$ $\mathrm{mmol} / \mathrm{l}$, none of whom was subsequently diagnosed as diabetic over 9.5 years of follow up, the number of undiagnosed diabetics will be small and will not alter the findings from a study of this size. The stability of the $R R$ estimates after exclusion of the 100 men who developed non-insulin dependent diabetes mellitus during the follow up, supports this argument. Moreover, if the excess of IHD events observed at the 80th centile (a serum glucose concentration $\geqslant 6.1 \mathrm{mmol} / \mathrm{l}$ ) was due to misclassification of undiagnosed diabetics, one would expect to find evidence of a further increase in risk at higher glucose levels, such as at the 90 th or 95 th centiles where the risk of subsequent non-insulin dependent diabetes mellitus (and presumably the prevalence of undiagnosed diabetes) rises sharply. No evidence of a further increase in risk at these higher glucose concentrations was found.

In the International Collaborative Group report, no significant association between glucose quintile and IHD mortality was detected in eight of eleven studies of middle aged men in eight countries, and in only one study was a strong independent association observed. ${ }^{6}$ Protocols and methods for assessing glycaemia varied considerably between these studies and in all but two studies there were fewer than 200 IHD events.

In the 10 year follow up data from the Whitehall study, there was clear evidence of a threshold effect, with an approximately twofold increased risk of IHD observed in the upper $5 \%$ of the post-load glucose distribution. This effect was independent of major cardiovascular risk factors, including age, obesity, blood pressure, smoking, cholesterol level, and ECG abnormalities. ${ }^{2}$ A similar threshold effect of the post load-glucose level on IHD mortality was reported from the Paris Prospective Study data. ${ }^{8}$ By contrast, Barrett-Connor et al. reported a continuous, independent relationship between fasting plasma glucose and IHD mortality in men aged 40-79 years in a southern California community. ${ }^{9}$ Similarly, in the Honolulu Heart Program data a linear relationship between glucose concentration one hour after glucose load and IHD mortality was observed. ${ }^{10}$ Other major studies reported in the last decade include the Tecumseh study in which at 18 years follow up there was a weak linear relation between asymptomatic hyperglycaemia and IHD in men (142 deaths) but not in women (71 deaths). ${ }^{26}$

Not all studies reported since the collaborative group analysis support an independent association between asymptomatic hyperglycaemia and IHD. In the Chicago Heart Association Detection Project data, asymptomatic hyperglycaemia (after glucose load) was not an independent predictor of IHD mortality (286 events) at nine years follow up in 11220 middle aged men. ${ }^{27} \mathrm{An}$ independent association of borderline significance was observed in women. In the Bedford study, borderline hyperglycaemia after glucose challenge was predictive of IHD mortality only among women. ${ }^{28}$ In 12 year data from the Gothenburg study, however, no association between the fasting blood glucose concentration and IHD end points was detected in a group of 1462 women aged 38 to 60 years with 28 events. ${ }^{29}$

Factors influencing mortality and event rates are likely to differ in men with and without prevalent IHD at screening. Most previous studies have excluded men with ECG evidence of myocardial infarction ${ }^{6}$ or have adjusted for this factor in multivariate analysis. ${ }^{2}$ Differences in exclusion criteria for this factor may account for some of the inconsistency in current data. Additional factors of relevance in this context include the low reliability with which glucose is measured, the variable follow up periods, and, as discussed, the relatively small number of events and deaths in many of the previous studies.

In previous work we have reported a graded, inverse relation between the level of physical activity and subsequent major IHD events. ${ }^{14}$ We have also shown in cross sectional data from the British Regional Heart Study, that physical activity is inversely associated with the serum glucose concentration. ${ }^{30}$ One might therefore anticipate that physical activity would be an important confounder in the relation between glucose and IHD. In the British Regional Heart Study data, however, the effect of 
physical activity on serum glucose is observed only among those engaged in relatively high levels of activity ${ }^{30}$ and is exerted predominately on those men with a non-fasting glucose level $\geqslant 7.8 \mathrm{mmol} / \mathrm{l}$ - that is, at or above the $96 \mathrm{th}$ rather than the 80th centile).

The basis for this independent association between hyperglycaemia and IHD remains obscure, though it is likely that a number of different mechanisms, both direct and indirect, are involved. Mechanisms proposed to date include increased activity of the polyol pathway, glycosylation of tissue proteins, glycosylation and altered catabolism of lipoproteins, and abnormalities of platelet function and the coagulation system. ${ }^{4531}$ It may be that hyperglycaemia is simply a marker for more fundamental abnormalities in carbohydrate and lipid metabolism, centered on insulin resistance with hyperinsulinaemia. ${ }^{32}$ Thus in the Paris Prospective Study data, glucose was not an independent predictor of IHD after adjustment for plasma insulin. ${ }^{33}$ Alternatively, it is suggested that hyperglycaemia and non-insulin dependent diabetes mellitus may be linked to IHD via common genetic antecedents ${ }^{34}$ or perhaps via intrauterine or early environmental factors. ${ }^{35}$

The British Regional Heart Study is a British Heart Foundation research group. Support is also provided by the Stroke Association and the Department of Health. Biochemical estimations were carried out at the Wolfson Research Laboratories, Queen Elizabeth Hospital, Birmingham. Dr I Perry was supported by the Wellcome Trust.

1 Kannel WB, McGee DL. Diabetes and cardiovascular disease: the Framingham study. $\mathcal{F} A M A$ 1979;241:2035-8.

2 Fuller JH, Shipley MJ, Rose G, Jarrett RJ, Keen H. Mortality from coronary heart disease and stroke in relation to degree of glycaemia: the Whitehall study. $B M F$ 1983;287: 867-70.

3 Manson JE, Colditz GA, Stampfer MJ, et al. A prospective study of maturity onset diabetes mellitus and risk of coronary heart disease and stroke in women. Arch Intern Med 1991;151:1141-47.

4 Salonen JT. Non-insulin-dependent diabetes and ischaemic heart disease. $B M \Im$ 1989;298:1050-51.

5 Wittels EH, Gotto AM. Clinical features of ischaemic heart disease in diabetes mellitus. In: Alberti KGMM, DeFronza disease in diabetes mellitus. In: Alberti KGMM, DeFronza RA, Keen H, Zimmet P eds. International textbook of

6 Stamler R, Stamler J. Asymptomatic hyperglycaemia and coronary heart disease. A series of papers by the International Collaborative Group based on studies in 15 populations. Joint Discussion. $\mathcal{f}$ Chrn Dis 1979;32:82937 .

7 Fuller JH, Shipley MJ. Hyperglycaemia as a cardiovascular risk factor. Postgrad Med F 1989;65(suppl 1):S30-32.

8 Eschwege E, Ducimetiere P, Papoz L, Claude JR, Richard $\mathrm{JL}$. Blood glucose and coronary heart disease. Lancet 1980; ii:472-3.

9 Barrett-Connor E, Wingard DL, Criqui MH, Suarez L. Is borderline fasting hyperglycaemia a risk factor for carborderline fasting hyperglycaemia a risk facto

10 Donahue RP, Abbott RD, Reed DM, Yano K. Postchallenge glucose concentration and coronary heart disease in men glucose concentration and coronary heart disease in men
of Japanese ancestry. Honolulu heart program. Diabetes 1987;36:689-92.
11 Ganda OP, Day JL, Soeldner JS et al. Reproducibility and comparative analysis of repeated intravenous and oral comparative analysis of repeated intravenous and
glucose tolerance tests. Diabetes 1978;27:715-25.

12 Yudkin JS, Alberti KGMM, McLarty DG, Swai ABM Regular review: impaired glucose tolerance. $B M \mathcal{F} 1990$; 301:397-402.

13 Helmrich SP, Ragland DR, Leung RW, Paffenberger RS. Physical activity and reduced occurrence of non-insulindependent diabetes mellitus. N Engl f Med 1991;325: $147-52$

14 Shaper AG, Wannamethee G. Physical activity and ischaemic heart disease in middle-aged British men. $B M \mathcal{J}$ 1991;66:384-94.

15 Shaper AG, Pocock SI, Walker M, Phillips AN, Whitehead TP, Macfarlane PW. Risk factors for ischaemic heart disease: the prospective phase of the British regional heart study. $\mathcal{F}$ Epidemiol Community Health 1985;39:197-209.

16 Shaper AG, Pocock SJ, Walker M, Cohen NM, Wale CJ, Thomson AG. The British regional heart study: diovascular risk factors in middle-aged men in 24 towns. BMF 1981;283:179-86.

17 Cook DG, Shaper AG, Thelle DS, Whitehead TP. Serum uric acid, serum glucose and diabetes: relationships in a uric acid, serum glucose and diabetes: relationships

18 Thelle DS, Shaper AG, Whitehead TP, Bullock DG, Ashby $\mathrm{D}$, Patel I. Blood lipids in middle-aged British men. $\mathrm{Br}$ Heart f 1984;49:205-13.

19 Medical Research Council Working Party. MRC trial of mild hypertension: principal results. BMF 1985;291:97-104.

20 Walker M, Shaper AG. Follow-up of subjects in prospective studies in general practice. $\mathcal{F} R$ Coll Gen Pract 1984;34: 197-209.

21 Pocock SJ, Ashby D, Shaper AG, Walker M, Broughton PMG. Diurnal variations in serum biochemical and haematological measurements. F Clin Pathol 1989;42:1729.

22 Prevalence of ischaemic heart disease in middle-aged British men. Br Heart F 1984;51:595-605.

23 Phillips AN, Shaper AG, Pocock SJ, Walker M. The role of risk factors in heart attack occurring in men with preexisting IHD. Br Heart $f$ 1988;60:404-10.

24 Pocock SJ, Shaper AG, Phillips AN. Concentration of HDLcholesterol, triglyceride and total cholesterol in ischaemic cholesterol, triglyceride and total cholest

25 Pyorala K, Laakso M, Uusitupa M. Diabetes and atherosclerosis: An epidemiologic view. Diabetes Metab Rev 1987; 3:463-524.

26 Butler WJ, Ostrander LD, Carman WJ, Lamphiear DE. Mortality from coronary heart disease in the Tecumseh Study. Long term effects of diabetes mellitus, glucose tolerance and other risk factors. Am $\mathcal{F}$ Epidemiol 1985;121: 541-7.

27 Pan W-H, Cedres LB, Liu K, et al. Relationship of clinical diabetes and asymptomatic hyperglycaemia to risk of coronary heart disease mortality in men and women. $A m$ Epidemiol 1986;123:504-16,28.

28 Jarret RJ, McCartney PP, Keen $\mathrm{H}$. The Bedford survey: ten year mortality rates in newly diagnosed diabetics, borderline diabetics and normoglycaemic controls and risk Diabetologia 1982;22:79-84.

29 Lapidus L, Bengtsson C, Blohme G, Lindquist O, Nystrom E. Blood glucose, glucose tolerance and manifest diabetes in relation to cardiovascular disease and death in women. in relation to cardiovascular disease and death in women. A 12-year follow-up of participants in the population study
of women in Gothenburg, Sweden. Acta Med Scand 1985; of women in

30 Perry IJ, Wannamethee G, Walker M, Shaper AG. Sporting activity and hyperglycaemia in middle-aged men. Diabetes Care 1993;16:581-3.

31 Ganda OP. Pathogenesis of macrovascular disease in the human diabetic. Diabetes 1980;29:931-42.

32 Reaven GM. Role of insulin resistance in human disease. Diabetes 1988;37:1595-607

33 Fontbonne AM, Eschwege EM. Insulin and cardiovascular disease. Paris Prospective Study. Diabetes Care 1991;14: 461-9.

34 Jarrett RJ, Shipley MJ. Type 2 (Non-Insulin-Dependent Diabetes and cardiovascular disease - putative association via common antecedents; further evidence from the Whitehall study. Diabetologia 1988;31:737-40.

35 Hales CN, Barker DJP, Clark PMS, Cox LJ, Fall C, Osmond C, Winter PD. Fetal and infant growth and impaired C, Winter PD. Fetal and infant growth and impai
glucose tolerance at age 64. BMf 1991;303:1019-22. 